\title{
Macrophages in Organ Transplantation
}

\author{
Farideh Ordikhani ${ }^{1}$, Venu Pothula ${ }^{1}$, Rodrigo Sanchez-Tarjuelo ${ }^{1}$, Stefan Jordan ${ }^{1}$ \\ and Jordi Ochando ${ }^{1,2 *}$ \\ 1 Department of Oncological Sciences, Icahn School of Medicine at Mount Sinai, New York, NY, United States, \\ ${ }_{2}^{2}$ Immunología de Trasplantes, Centro Nacional de Microbiología, Instituto de Salud Carlos III, Madrid, Spain
}

\section{OPEN ACCESS}

Edited by:

Heth Roderick Turnquist,

University of Pittsburgh, United States

Reviewed by:

Gilles Benichou,

Harvard Medical School, United States

Mahzad Akbarpour,

University of Chicago Medicine,

United States

Paloma Riquelme,

University Medical Center

Regensburg, Germany

*Correspondence:

Jordi Ochando

Jordi.ochando@mssm.edu

Specialty section:

This article was submitted to Alloimmunity and Transplantation,

a section of the journal

Frontiers in Immunology

Received: 13 July 2020

Accepted: 20 October 2020

Published: 30 November 2020

Citation:

Ordikhani F, Pothula V.

Sanchez-Tarjuelo R, Jordan S and Ochando J (2020) Macrophages in

Organ Transplantation.

Front. Immunol. 11:582939. doi: 10.3389/fimmu.2020.582939
Current immunosuppressive therapy has led to excellent short-term survival rates in organ transplantation. However, long-term graft survival rates are suboptimal, and a vast number of allografts are gradually lost in the clinic. An increasing number of animal and clinical studies have demonstrated that monocytes and macrophages play a pivotal role in graft rejection, as these mononuclear phagocytic cells recognize alloantigens and trigger an inflammatory cascade that activate the adaptive immune response. Moreover, recent studies suggest that monocytes acquire a feature of memory recall response that is associated with a potent immune response. This form of memory is called "trained immunity," and it is retained by mechanisms of epigenetic and metabolic changes in innate immune cells after exposure to particular ligands, which have a direct impact in allograft rejection. In this review article, we highlight the role of monocytes and macrophages in organ transplantation and summarize therapeutic approaches to promote tolerance through manipulation of monocytes and macrophages. These strategies may open new therapeutic opportunities to increase long-term transplant survival rates in the clinic.

Keywords: macrophages, immune tolerance, trained immunity, organ transplantation, nanotherapy

\section{INTRODUCTION}

Organ transplantation is a life-saving strategy for thousands of patients with end-stage organ failure. Patients who find a compatible donor and receive a transplant are treated daily with multi-drug combinations designed to prevent rejection of the transplanted organ. Thanks to great progress in surgical techniques and immunosuppressive drugs, the percentage of short-term allograft rejection events has declined and 1-year allograft survival rates are above $90 \%$ (1). However long-term graft survival rates remain suboptimal $(2,3)$, arguing in favor of additional mechanisms of immune regulation associated with chronic allograft rejection that escape current immunosuppressive therapy.

To promote long-term organ transplant survival in the absence of chronic immunosuppressive therapy, transplant immunologists have historically focused on targeting the adaptive immune response. This is in response to early work on allograft rejection, which demonstrated that $\mathrm{T}$ cells are both necessary and sufficient for allograft rejection $(4,5)$. More recent work has focused on developing novel tolerogenic protocols that target the adaptive immune response using methods that include depletion of effector T cells (6), induction of $\mathrm{CD}^{+} \mathrm{CD}^{+} 5^{+} \mathrm{Foxp} 3^{+}$regulatory T cells (7) and blockade of co-stimulatory signals (8). The latter was achieved using monoclonal antibodies $(\mathrm{mAb})$ or immunoglobulins (Ig) against cell surface molecules (CD4 (9); CD4 + DST (10); CD3 (11); 
non-depleting CD3 (12); CD40L (13); CD40L + CD28 (14); LFA- $1^{+}$+ ICAM-1 (15); CD2 (16); CD2 + CD3 (17); LFA3-Ig (18); CD80 and CD86 (19); CD40 (20); and CTLA4-Ig (21) (Figure 1A). While promising results have been obtained using these therapeutic approaches in experimental animal models, translation of these tolerance promoting methodologies that target innate immune cells in the clinic remain largely elusive (Figure 1B). Considering that consistent induction donor specific unresponsiveness remains a difficult task in the clinic, there is a major unmet need for the development of additional immune regulatory programs to improve long-term allograft survival in the clinical practice. Since innate immune cells participate in allograft recognition, developing therapeutic approaches that target myeloid cells in the clinic could open novel avenues to improve long-term transplantation outcomes.

It is widely accepted that allograft rejection is the result of a complex series of interactions between both the innate and the adaptive immune systems $(22,23)$. Recent advances in our understanding of the mechanisms that determine the outcome of the immune response to transplanted organs have highlighted the importance of the innate immune response (24). This ancient part of the immune system precedes cellular and humoral immunity and consequentially regulates the function of the adaptive immune response. The innate immune response initiates inflammatory signals as a defense mechanism against pathogens and tissue injury. Non-self-inflammatory stimuli induced by exogenous infectious agents are considered pathogen-associated molecular patterns (PAMPs), while tissue injury is recognized by self-derived damage-associated molecular patterns (DAMPs). Both PAMPs and DAMPs are recognized through pattern recognition receptors (PRRs), which include Toll-like receptors (TLR), NOD-like receptors (NLR) and C-type lectin receptors. PRRs are expressed on the cell surface and in the cytoplasm of innate immune cells, including macrophages, and mediate intracellular signaling cascades leading to transcriptional expression of inflammatory mediators (25).

Macrophages belong to the mononuclear phagocyte system and have a dual role in allograft transplantation, either triggering inflammatory response or inducing a tolerogenic environment (26). Local activation of macrophages through PRRs can lead to upregulation of major histocompatibility complex (MHC) and costimulatory molecules (signals 1 and 2), as well as the production of pro-inflammatory cytokines (signal 3 ) which result in $\mathrm{T}$ cell proliferation and differentiation $(27,28)$. More recently, it was demonstrated that macrophages adopt a long-term proinflammatory phenotype following an initial PRR stimulation of the C-type lectin receptor dectin-1, which results in a non-specific memory of the innate immune cells mediated by epigenetic reprogramming (29). This novel macrophage functional state has been termed trained immunity and is associated with proinflammatory cytokine production (TNF $\alpha$ and IL-6) after a second PRR stimulatory signal with TLR4 agonists (30). Understanding the immune biology of trained immunity has important implications for the design of novel therapeutic approaches. Preventing the accumulation of trained macrophages while promoting the development of regulatory macrophages represents an attractive, innovative approach to promote organ transplant acceptance. Herein, we highlight recent studies on the role of macrophages in organ transplantation and summarize the therapeutic potential of targeting macrophages for the induction of tolerance.

\section{MACROPHAGE HETEROGENEITY AND PLASTICITY}

Monocytes and macrophages are key elements of innate immunity and have crucial roles in host defense, inflammation and tissue
A

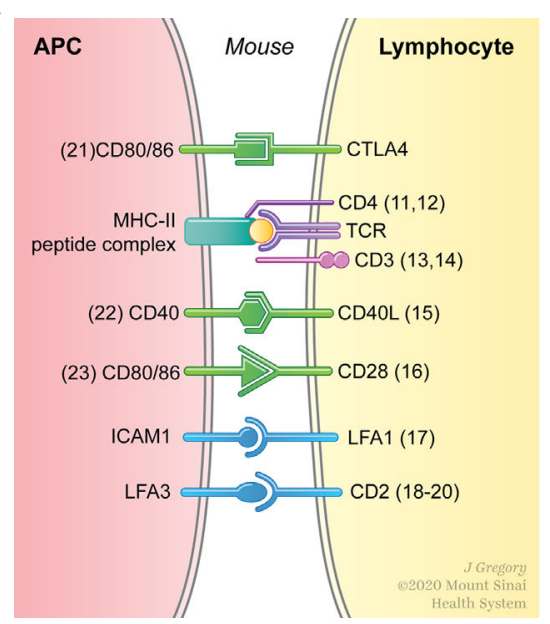

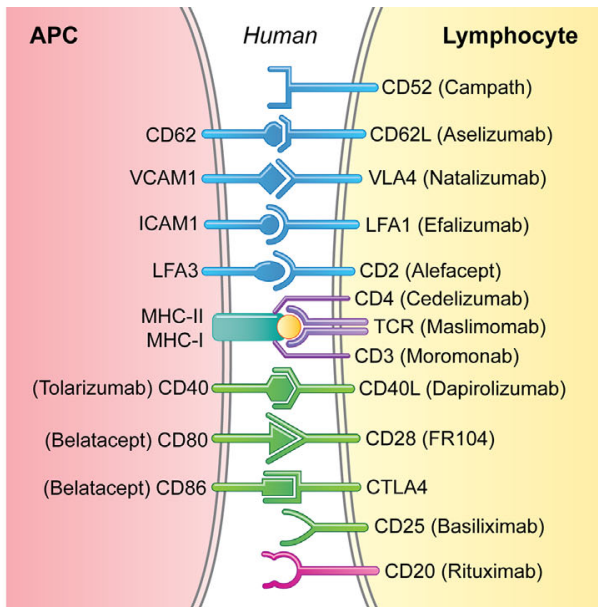

FIGURE 1 | Interfering with binding of the TCR to antigenic peptide complexed with MHC (signal 1) and engagement of co-stimulatory molecules (signal 2) prevents $T$ cell activation. (A) Prolonged allograft survival and induction of tolerance has been achieved in experimental animal models buy targeting signals 1 and 2 in both $T$ cells and antigen presenting cells (APC). (B) The clinical translation of therapeutic approaches that specifically target APC in vivo remain largely elusive. 
homeostasis $(31,32)$. Monocytes originate from myeloid progenitor cells in the bone marrow and circulate in the blood for several days before entering the tissue and differentiating into macrophages $(33,34)$. Monocyte-derived macrophages also have key roles in clearing pathogens and cell debris, antigen presentation and initiating adaptive immune responses (35). To do so, macrophages acquire specialized functions according to the stimuli present in the environment. In relation to their activation, Mills et al. proposed two phenotypes: classical (M1) versus alternative (M2), in analogy to T helper cells Th1 and Th2 (36, 37). M1/M2 macrophages are functionally distinct with M1 macrophages shifted to nitric oxide (NO) and citrulline secretion, while M2 macrophages shifted toward production ornithine and polyamine secretion $(36,37)$. Consequentially, M1-derived NO inhibits $\mathrm{T}$ cell proliferation and exhibits a potent microbicidal activity, while M2-derived ornithine promotes cell proliferation and repair through polyamine and collagen synthesis (38-40). Over the past few years, this nomenclature has been a matter of debate due to the difficulty of including within M1 and M2 classification the multiple phenotypes adopted by macrophages. While in vitro activation of macrophages allowed us to better understand the developmental requirements of different macrophage subsets, in vivo studies are more complicated because the stimuli they encounter are multiple, complex and occur simultaneously $(31,41,42)$.

Various stimuli control the expression of macrophage genes encoding cytokine receptors, cell activation markers and cell adhesion molecules (Figure 2). Classic or M1 macrophage activation increases in response to PAMPs, DAMPs and pro- inflammatory cytokines such as interferon- $\gamma($ IFN- $\gamma)$ and tumornecrosis factor (TNF) $(43,44)$. The environment favors the production of inflammatory chemokines by M1 macrophages, which induce lymphocyte recruitment. Among the chemokines produced by these M1 macrophages are CXCL9 and CXCL10, strongly associated with Th1 immune response $(45,46)$ and CXCL16, which maintain M1 polarization (47). Upon activation, M1 macrophages produce high levels of pro-inflammatory cytokines such as TNF, IL-1 $\beta$, IL-6, IL-12 and IL-23, which may result in functional $\mathrm{CD}^{+} \mathrm{T}$ lymphocyte polarization toward Th1 (48-51) or Th17 (52-54). In addition, M1 macrophages produce high levels of inducible nitric oxide synthase 2 (iNOS2) and reactive oxygen intermediates (ROI) that participate in removing bacteria, viruses and parasites. Phenotypically, costimulatory molecules such as CD40, CD80 and CD86, important in antigen presentation, are upregulated in M1 macrophages in conjunction with major histocompatibility complex class II (MHC-II) (55-57).

In contrast, M2-polarized macrophages, also known as alternatively activated macrophages, are important in tissue repair. The M2 phenotype contains different macrophage populations with separated functions, which can be polarized by several stimulatory factors. Based on the stimuli and transcriptional changes, Mantovani and Röszer divided the M2 phenotype into M2a, M2b, M2c and M2d subtypes $(58,59)$. The mutual characteristics of these subtypes are high secretion of IL10 and low IL-12 levels, in conjunction with the generation of arginase-1 (Arg-1). M2a macrophages are induced by IL-4 and IL-13, express high levels of mannose receptor (CD206) and

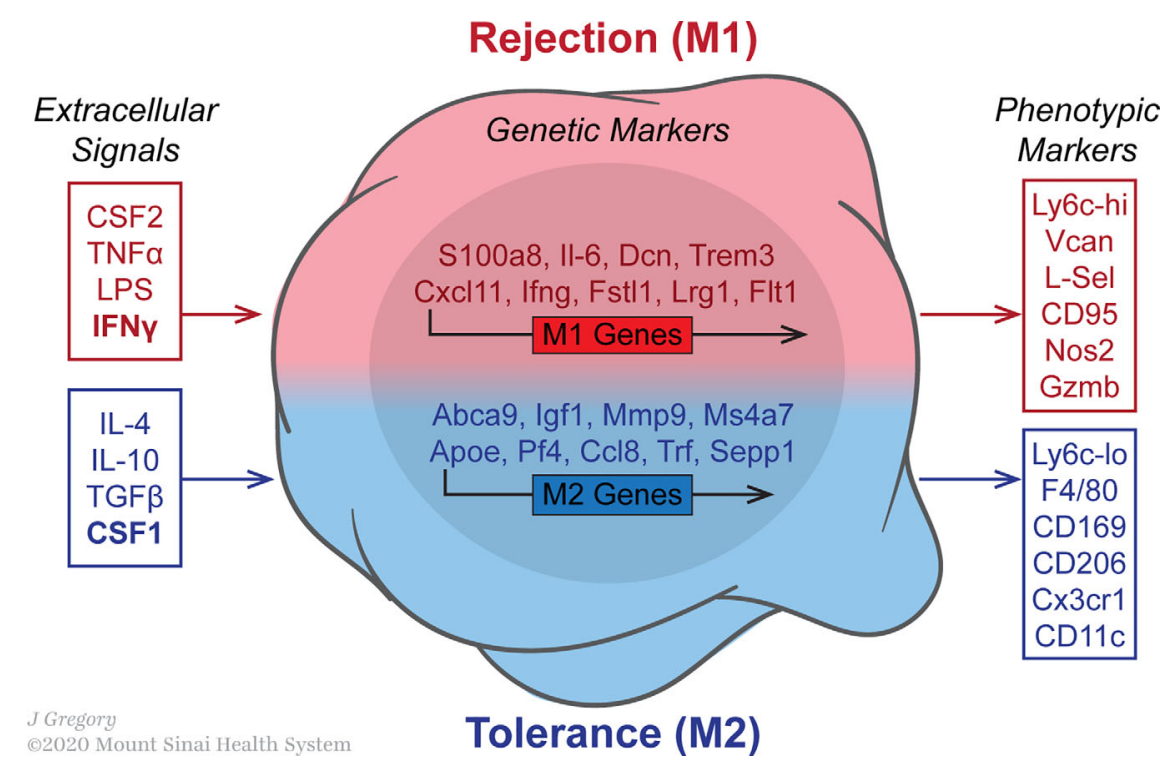

FIGURE 2 | Macrophages polarization in the transplanted allograft is influenced by various stimuli. The image indicates the expression of macrophage genes encoding cytokine receptors, cell activation markers and cell adhesion molecules. Data was acquired from published microarray obtained from graft-infiltrating macrophages on day 5 post-transplantation in either untreated rejecting or anti-CD4OL mAb treated mice. The GEO accession number for the microarray data reported in this figure is GSE68648. 
secrete pro-fibrotic factors, such as TGF- $\beta$, to contribute towards tissue repair (60-62). M2b macrophages have phenotypical and functional similarities with regulatory macrophages. They are activated by TLR or IL-1R agonists and produce both pro and anti-inflammatory cytokines, such as TNF- $\alpha$, IL-1 $\beta$, IL6 and IL10 (41, 63). M2c macrophages, also known as inactivated macrophages, are induced by IL-10 and display antiinflammatory functions. M2c secrete IL-10 and TGF- $\beta(59,64)$ and are efficient at phagocytosis and elimination of apoptotic cells (65). M2d macrophages have phenotypical and functional similarities with tumor-associated macrophages (TAMs). They are induced by A2 adenosine receptor (A2R) and IL-6 (66-68) and secrete IL-10, TGF- $\beta$ and vascular endothelial growth factor (VEGF) to favor angiogenesis and cancer metastasis (68-70).

The need to update the M1/M2 classification has been evidenced in numerous studies addressing signaling pathways and genetic signatures associated with M1/M2 polarization (7175). M1 and M2 share many genes implicated in cellular functions, such as phagocytosis, metabolism and cytokine production. IL-8, Tissue Factor and Leukocyte extravasation signaling pathways are shared among M1 and alternatively activated M2 $(76,77)$. On the other hand, recent works show specific signatures for M1 and M2 (78). For example, Jablonski et al. identified a new set of common and distinct M1 and M2 macrophage genes. They showed that CD38, Gpr18 and Fpr2 were M1-specific while c-Myc and Egr2 were M2-specific genes, proposing a new way to define both states of polarization based on their phenotypes: $\mathrm{CD}_{3}{ }^{+}$Egr2 ${ }^{-}$(M1 macrophages) and $\mathrm{CD}^{-} 8^{-} \mathrm{Egr}^{+}$(M2 macrophages) (71). In addition, Buscher et al. demonstrated a strong gene-environment interaction in activated macrophages using a hybrid mouse diversity panel (HMDP). They showed different genetic signatures associated with lipopolysaccharide (LPS) responsiveness among a wide spectrum of macrophage phenotypes from several different inbred strains (72). Recently, Orecchioni et al. compared both transcriptomes obtained from Jablonski (in vitro) and Buscher (in vivo) to define differential signatures present in M1/M2 macrophages (79) and concluded that Fc $\gamma$ receptor-mediated phagocytosis, MAPK signaling, MAPK, JAK1 and JAK3 signaling are upregulated in M1 upon LPS activation. These pathways control several inflammatory genes that allow the macrophages to exhibit their pro-inflammatory properties (80, 81 ). In contrast, the main pathways specifically expressed in M2 are adipogenesis, fatty acid synthesis and integrin signaling pathways, which are important for tissue infiltration, removal of necrotic tissue and initiation of tissue regeneration (82).

While bone marrow monocytes are mobilized early after transplantation and recipient monocyte-derived macrophages represent the majority of macrophages in the transplanted organ (83), it is important to acknowledge the immune regulatory role of tissue resident donor macrophages. Tissueresident macrophages (TRMs) arise from fetal liver or yolk-sac progenitors and are phenotypically distinct from monocytederived macrophages in steady state conditions (84). While TRMs are primarily characterized by the expression of CD11b, F4/80, CD64, CD68 and MerTK and low levels of MHC-II on the cell surface in mice, monocyte-derived macrophages are characterized by CD11b, CD209, CD64 and MerTK expression on the cell surface (85). TRMs are functionally considered to be immunosuppressive because of their fundamental roles in maintaining homeostasis, inhibiting $\mathrm{T}$ cell activation and promoting the resolution of inflammation $(75,86)$. TRMs are divided into subpopulations according to their anatomical sites and functionality. For instance, Kupffer cells in liver $(87,88)$ or alveolar macrophages in lung (89) exhibit critical roles in generating CD4 regulatory $\mathrm{T}$ cells (Treg) and promoting tolerance. In the context of organ transplantation, Terry Strom and colleagues identified a subset of donor TRM that express high levels of the phosphatidylserine receptor TIM4 and CD169. The study demonstrated that this population of macrophages migrates to the draining lymph nodes following oxidative stress during ischemia-reperfusion injury (IRI) associated with transplantation and induces antigen-stimulated Treg. Interestingly, these M2-like TIM-4+CD169+ donor TRM were demonstrated to be immunoregulatory and to promote the engraftment in a murine cardiac allograft model (90). Contrary to this view, it has been suggested that ischemia/reperfusion primes innate immune cells for an excessive response to a subsequent inflammatory, which promotes organ injury. In the lung, alveolar macrophages under shock/resuscitation events increase their TLR4 expression in the cell surface due to oxidative stress (91). As a result, alveolar macrophages are primed and exhibit an exaggerated LPS response following a secondary stimulation. The source of the endotoxin is not clear, but it has been suggested that LPS may leak from the gut under ischemia/reperfusion conditions (92). This has major implications in lung transplantation as oxidative stress induced during IRI, coupled with an increase in the endotoxin levels in the donor organ is associated with increased neutrophil recruitment as well as physiological markers of allograft injury mediated by tissue resident alveolar macrophages through TLR4/ MyD88 dependent pathways (93). Consequentially, presence of endotoxin in the lung predisposes the donor organ to the fatal syndrome of primary graft dysfunction (PGD) and compromises the survival of the allograft following lung transplantation. Overall, the data suggests that while TRMs present in the donor organs may favor immunoregulatory mechanisms that promote allograft engraftment (94), their suppressive activity may be reversed toward a pro-inflammatory functional state (95), compromising organ transplant survival.

\section{Macrophages and Rejection}

Macrophage accumulation has long been recognized as a feature of allograft rejection (96). The total number of graft infiltrating macrophages correlates with worse clinical outcomes $(97,98)$ and with acute allograft dysfunction in kidney transplant recipients (99). Early studies from Hancock and colleagues demonstrated that macrophages represent the majority of cells that infiltrate an allograft during severe rejection episodes (100). Using immunohistochemical approaches, their study reported that macrophages represent $60 \%$ of graft-infiltrating cells in severe rejection, $52 \%$ in mild rejection and $38 \%$ in moderate rejection (100). Looking at the patterns of graft-infiltrating cells during the first days after transplantation, various human studies 
have shown that the initial accumulation of monocytic cells occurs in all grafts (rejecting and non-rejecting) (101) and that infiltration of kidney allografts by macrophages within the first week of transplantation is associated with worser clinical outcomes (102). Similarly, Schreiner et al. showed an initial accumulation of macrophages in the first $24-48 \mathrm{~h}$ after transplantation for both donor kidney allografts and isografts, with a marked increase in monocytes/macrophages being observed only in allografts $96 \mathrm{~h}$ after engraftment. As such, it is not surprising that depletion of macrophages has been used to attenuate graft injury and decrease inflammation in acute rejection models $(103,104)$. To this end, Jose et al. by depletion of macrophages with liposomal-clodronate in a renal transplant rat model showed the contribution of macrophages to tissue damage during acute rejection (105). In another study, Ma et al. demonstrated that the depletion of monocytes/ macrophages with $\mathrm{c}$-fms kinase inhibitor resulted in less renal allograft dysfunction and structural damage compared to the vehicle-treated rats (106). Data from our laboratory demonstrated early after transplantation that M1-like monocytic precursors leave the bone marrow and infiltrate heart allografts in transplanted mice (107). Importantly, while M1-like monocytes rapidly convert to M2-like regulatory macrophages in the allografts of transplant recipients under costimulatory blockade treatment with antiCD40L mAb, untreated recipients maintain M1-like inflammatory macrophages in the rejecting allografts (108). Interestingly, depletion of recipient $\mathrm{CD} 11 \mathrm{~b}$ cells using CD11bDTR mice as recipients, prevented the induction of tolerance. This suggests that initial events that regulate macrophage polarization (M1 to M2) rather than depletion may control the fate of the immune response, since depletion of macrophages may affect the protective role of wound healing and tissue remodeling macrophages that are required to restore homeostasis in the donor organ after the transplant surgical procedure.

Despite the significant progress in determining the roles of macrophages in acute graft rejection, the mechanisms by which macrophages mediate tissue injury are not completely understood. One of the suggested mechanisms by which macrophages mediate graft loss is through the production of nitric oxide contributing to the endothelial cell cytotoxicity and tubular injury (103). Acute rejection in heart transplant recipients was associated with severe fibrosis in 1-year biopsies, which was associated with higher $\mathrm{CD} 68^{+} \mathrm{CD} 163^{+} \mathrm{M} 2$ macrophages compared to barely present $\mathrm{CD} 68^{+} \mathrm{CD} 80^{+} \mathrm{M} 1$ macrophages in graft (109). Similarly, infiltrating macrophages in renal allograft 1-year after transplantation exhibited an M2 phenotype with $\mathrm{CD} 8^{+} \mathrm{CD}^{206^{+}}$dual staining (110). It has also been suggested that $\mathrm{CD} 16^{+}$monocytes might be responsible for the development of acute allograft rejection after liver transplantation, which may be associated with inhibition of Treg cells (111). Furthermore, whole-genome transcriptome analysis of biopsy samples identified an inflammatory macrophage polarization-specific gene signature, which is upregulated during acute rejection (112). In fact, the degree of macrophage infiltration correlates with increased incidence of allograft rejection (34). Consistent with the increased of macrophage/monocytes infiltration, the level of monocyte colony stimulating factor (M-CSF), a key cytokine in monocyte recruitment, is elevated in the graft during clinical rejection (113). Moreover, activated monocytes are detectable in the circulation before the clinical symptoms of acute rejection occur (114).

Gradual replacement with recipient-derived macrophages over time leads to chronic rejection through mechanisms that involve cell death, fibrosis, smooth muscle proliferation and cytokine-mediated inflammation (115). Although inflammation is supposed to be short lived and self-limited, acute inflammation can sometimes shift toward a long-lived and self-perpetuating chronic inflammatory response (116). Chronic inflammation develops within months to years after organ transplantation and is the major cause of long-term graft loss (115). The main feature of chronic rejection is obliterative vasculopathy, often accompanied by parenchymal fibrosis which results in ischemia, cell death and progressive graft failure $(115,117)$. Chronic rejection is characterized by infiltrating $\mathrm{T}$ cells and macrophages, although other cellular compartments include natural killer cells, dendritic cells, B cells and plasma cells also play a role in chronic rejection (116). However, the high number of infiltrating macrophages in the allograft, as well as their potential to produce cytokine/growth factor suggests the crucial role of macrophages as end-effector cells in a final common pathway toward cardiac allograft vasculopathy (CAV) independent of T-cell or B-cell alloreactivity (118).

Accumulation of alternatively activated M2-type macrophages is the major macrophage population localized in areas of interstitial fibrosis in chronic kidney allograft injury and correlates with the severity of fibrosis and graft rejection (110, 119). M2 polarization is considered to be anti-inflammatory, immunoregulatory and important for tissue repair and regeneration. However, during chronic rejection, the pro-fibrotic function of M2-polarized macrophages promotes interstitial fibrosis and contributes to graft failure (120). Graft-infiltrating macrophages during chronic rejection are a heterogeneous population expressing markers that are associated with M1 inflammation but also with an M2 immunoregulatory phenotype. It is possible though that immunoregulatory M2 cells are derived from $\mathrm{M} 1$ cells in the graft, when the pro-inflammatory microenvironment subsides over time. The predominance of a certain macrophage polarization state in the graft might determine the clinical success of the transplantation. In human kidney transplant recipients, a higher M2 ratio is associated with chronic glomerular injury and poorer graft function (121). Despite the apparent predominant role of M2 macrophages in chronic graft rejection, M1 macrophages might critically contribute with the production of eicosanoids, proteases, ROS and NO (122). To prevent chronic rejection, Liu et al. investigated the effect of macrophage depletion for a certain amount of time in a rat allogenic heart transplant model (123). Their results suggested that macrophage depletion after heart transplantation could alleviate chronic rejection through M2 polarization of regenerated macrophages, as well as the alternation of expression levels of IFN- $\gamma$, TNF- $\alpha$, MCP-1 and IL-10 (123). These approaches deplete macrophages and blocking monocyte recruitment by targeting CCR- and CXCR-mediated chemotaxis that reduce vasculopathy $(118,124,125)$. 
The granulocyte-macrophage colony-stimulating factor (GMCSF) and the macrophage colony-stimulating factor (M-CSF) are some of the known factors that regulate differentiation, proliferation, and function of tissue macrophages and determine the outcome of the immune response (126). While GM-CSF induces a state in which macrophages are primed for M1, MCSF induces M2 macrophage polarization $(125,127)$. In a recent study, our group elucidated the molecular mechanisms behind CSF-1-mediated macrophages polarization. Our results exhibited that graft-infiltrating neutrophils in tolerized recipient allografts secreted higher levels of M-CSF compared to neutrophils from untreated rejecting mice, suggesting a potential role of M-CSF producing neutrophils in mediating regulatory M2 macrophage accumulation in the transplanted allograft (128).

Manipulation of M1/M2 polarization represents another therapeutic approach to prevent allograft rejection. Xian Li and colleagues demonstrated that M1/M2 macrophage polarization is dependent on tumor-necrosis factor receptor-associated factor 6 (TRAF6) and mammalian target of rapamycin (mTOR), respectively (129). While mice deficient for TRAF6 in macrophages prevents accumulation of M1 macrophages in recipient mice that develop severe transplant vasculopathy, deletion of mTOR prevents accumulation of M2 macrophages in long-term allograft survival without histological indications of chronic rejection, emphasizing the role of M2-polarized macrophages in chronic allograft rejection (129). The Xian Li laboratory further investigated differences between M1 and M2 macrophages and identified the adenosine triphosphate (ATP)gated ion channel (P2x7r) as a marker of M2 cells (130). Interestingly, blockade of $\mathrm{P} 2 \times 7 \mathrm{r}$ using oxidized ATP, prevented $\mathrm{M} 2$ polarization in vitro and graft-infiltration in vivo, leading to long-term heart allograft survival. This study demonstrated that pharmaceutical targeting of M2 graft-infiltrating macrophages during chronic rejection is a promising strategy to prolong graft survival. Consistent with this view, specific deletion of RhoA or inhibition ROCK kinases with a combination of Y27632, Fasudil and Azaindole inhibited vessel occlusion and tissue fibrosis, decreased M2 macrophage infiltration and abrogated chronic rejection of cardiac allografts $(131,132)$.

Besides their M1/M2 pro-inflammatory and immunoregulatory functions, it is also possible that macrophages contribute to graft rejection by additional mechanisms. Macrophages in biopsy specimens from patients with active chronic renal allograft rejection co-expressed the macrophage marker CD68 as well as the myofibroblast marker a-smooth muscle actin (a-SMA), suggesting that macrophages undergo a macrophage-tomyofibroblast transition leading to interstitial fibrosis and reduced graft function (133). Similarly, cells co-expressing macrophage and a-SMA markers were found in allografts in mice. These cells derived from recipient bone marrow cells, thus were infiltrating the graft and also co-expressed M2 marker CD206. Further mechanistic studies identified a crucial role for Smad3 in macrophage-to-myofibroblast transition (133).

One key feature of circulating monocytes is their ability to migrate to the inflamed tissue and to initiate the immune response against non-self antigens. Fadi Lakkis and colleagues reported that $\mathrm{F} 4 / 80^{-} \mathrm{Ly}_{6 \mathrm{C}^{+}}$neutrophils, F4/80 int $\mathrm{Ly}_{6 \mathrm{C}^{+}}$ monocytes and $\mathrm{F} 4 / 80^{\text {hi }} \mathrm{Ly} 6 \mathrm{C}^{-}$macrophages rapidly infiltrate sites of inflammation and elicit an allospecific immune response. Remarkably, in contrast to the allogeneic non-self recognition by $\mathrm{T}$ cells that recognize $\mathrm{MHC}$ molecules, macrophages were shown to recognize non-MHC molecules (134). Using B6-OVA $\left(\mathrm{H}-2^{\mathrm{b}}\right)$ and B6F1-OVA $\left(\mathrm{H}-2^{\mathrm{b} / \mathrm{d}}\right)$ donor heart grafts transplanted into $\mathrm{B} 6 \mathrm{Rag}^{-} I^{-} \gamma \mathrm{c}^{-} /^{-}\left(\mathrm{H}-2^{\mathrm{b}}\right)$ recipients, this group further demonstrated that only monocytes and DC from B6 $\mathrm{Rag}^{-} /^{-} \mathrm{\gamma c}^{-} /^{-}$recipient mice receiving B6F1-OVA (but not B6-OVA) grafts, were able to promote acute cellular rejection upon transfer of OVA antigen-specific $\mathrm{CD}^{+}$OT-II cells. The Lakkis laboratory, went on to demonstrate that monocytes and macrophages detect the polymorphic molecule signal regulatory protein $\alpha(\operatorname{SIRP} \alpha)$ on donor cells to initiate the innate alloresponse (135). SIRP $\alpha$ is a regulatory immunoglobulin superfamily receptor that represents a key member of the "donot-eat-me" signaling pathway that avoids the to avoid immune response by phagocytes. SIRP $\alpha$ is expressed by myeloid (136) and myeloid-derived suppressor cells (MDSC) that accumulate after organ transplantation and mediate allograft tolerance (137). Mechanistically, engagement of SIRP $\alpha$ with its ubiquitous ligand CD47 delivers inhibitory signals and suppresses the phagocytic function and inflammatory signaling of macrophages (138-140). In the context of organ transplantation, the Lakkis laboratory demonstrated that blocking SIRP $\alpha$ or CD47 with monoclonal antibodies induced graft dysfunction and rejection. Blocking of SIRP $\alpha-C D 47$ interaction results in MDSC differentiation into myeloid cells overexpressing MHC class II, CD86 costimulatory molecule and increased secretion of macrophage-recruiting chemokines leading to loss of tolerance (141). However, a donor allograft with a $\operatorname{SIRP} \alpha$ molecule that is mismatched with CD47 leads causes monocytic cell activation and initiation of the immune response to the transplanted organ (135). More recently, the Lakkis laboratory also demonstrated that polymorphisms in the SIRP $\alpha$ gene were required to induce monocyte memory is against non-self MHC molecules. In this study, it was demonstrated that deleting the PIR-A in the recipient or blocking the paired immunoglobulin-like receptorA (PIR-A) binding to donor MHC-I with a PIR-A3/Fc inhibits alloantigen specific memory of myeloid cells and promotes indefinite allograft survival in a murine kidney and heart transplant model (142). Overall, these studies provide compelling evidence demonstrating that monocytes initiate the immune response, determine the critical role of SIRP $\alpha$ polymorphic differences in the activation of graft reactive macrophages and that the immunological memory to innate myeloid cells can be potentially targeted to promote the induction of transplantation tolerance.

\section{Macrophages and Tolerance}

The participation of graft-infiltrating macrophages in the rapid, stereotypical inflammatory reactions that cause secondary tissue damage during ischemia-reperfusion injury (143) and acute episodes (144) has been long-recognized. However, we are also beginning to understand the vital role of suppressor macrophages in preventing rejection and re-establishment of tissue homeostasis after transplantation (145). Given their influence over transplant 
outcome, manipulating the balance between graft-protective and graft-destructive macrophage activities represents an attractive therapeutic strategy (146). Various approaches to controlling macrophage responses have been proposed, including adoptive cell therapy with regulatory macrophages (Mregs). In previous work, it was shown that treatment with ex vivo-generated CD11 $\mathrm{b}^{+}$ Ly6C ${ }^{-/ \text {low }}$ Ly6G ${ }^{-}$CD $169^{+}$Mregs could prolong fully-allogeneic heart graft survival in non-immunosuppressed mice (147). Mechanistically, Mregs can directly suppress $\mathrm{T}$ cell proliferation and survival through an iNOS-dependent pathway and the secretion of anti-inflammatory factors (148). More recently, Riquelme et al. demonstrated that Mregs induce TIGIT ${ }^{+}$FoxP $^{+}$ Tregs that produce IL-10 and non-specifically mediates bystander suppression of allo-stimulated CD4+ and CD8+ T cells (149). An

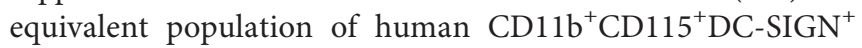
Mregs arises from peripheral blood $\mathrm{CD} 14^{+} \mathrm{CD} 16^{-}$monocytes that are cultured with M-CSF for 6 days prior to stimulation with IFN- $\boldsymbol{\gamma}$ (150). During this period, a gradual down-regulation of CD14 is observed, which may recapitulate the physiological transition of human M1-like $\mathrm{CD} 14^{+} \mathrm{CD}^{-} 6^{-}$inflammatory monocytes into $\mathrm{M} 2$-like $\mathrm{CD} 14^{-/ 1 \mathrm{ow}} \mathrm{CD} 16^{+}$resident macrophages. Interestingly, presence of human Mregs correlates with an increase in TIGIT $^{+} \mathrm{FoxP}^{+}$Treg in kidney transplant recipients (149), which is consistent with the preclinical experiments described above. In the clinical setting, Mregs are currently being investigated in humans in the ONEmreg12 trial, a phase-I/II study to minimize maintenance immunosuppression in kidney transplant recipients (151). This and previous clinical studies suggest Mregs could be used as a cell-based tolerancepromoting therapy, and for this purpose a good manufacturing practice-compliant production process for manufacturing an Mreg-containing cell product, known as "Mreg_UKR," has been established (152).

Suppressive macrophages are also be generated in recipient mice treated with costimulatory blockade. Our laboratory demonstrated that anti-CD40L mAb favors accumulation of

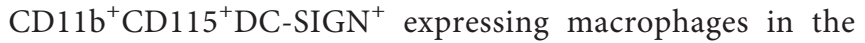
allograft, which promotes the expansion of Treg, while inhibited $\mathrm{CD}^{+} \mathrm{T}$ cell accumulation (108). Mechanistically, DC-SIGN macrophages produce regulatory IL-10 and their in vivo accumulation is controlled by $\mathrm{M}$-CSF, which is consistent with the Mreg development requirements, phenotype, and function as described by James Hutchinson laboratory above. Besides costimulatory blockade, nanoparticles have also been used to deliver immune regulatory agents to monocytes and macrophages in vivo (153). For example, delivery of mycophenolic acid (MPA) by means of PLGA nanoparticles (NP) results in a significant allograft survival prolongation compared to conventional MPA treatment in a murine model of skin transplantation. Mechanistically, Daniel Goldstein and colleagues demonstrated that uptake of NP-MPA by myeloid cells leads to upregulation of programmed death ligand-1 (PDL1), which results in decreasing their potential to prime alloreactive $\mathrm{T}$ cells associated with prolonged allograft survival (154). More recently, our laboratory described a promising strategy to induce long-term allograft survival through in vivo targeting of macrophages with nanobiologics. Our laboratory used an effective in vivo platform to deliver an mTOR inhibitor (mTORi) and NF-kB inhibitor (TRAF6i) via high density lipoprotein nanobiologics (HDL) in a murine vascularized heart transplant model. The HDL-based nanobiologics preferentially targeted myeloid cells and promoted M2 regulatory macrophage polarization, which resulted in prevention alloreactive CD8 $\mathrm{T}$ cell-mediated immunity and expansion of Treg (155). As a result, we believe that nanobiologics-based delivery of immunotherapeutic agents has great potential in organ transplantation as they improve the pharmacokinetics, minimize the off-target effects, maximize its dosage at the site of action, and can be as used as controlled release systems in a spatiotemporal manner (156). Taken together, it has become evident that the in vivo manipulation of macrophages through the use of nanobiologics represents a promising strategy for long-term allograft survival.

\section{Epigenetic Regulation of Macrophages and Innate Immune Memory}

Macrophages are highly plastic cells that adopt M1 and M2 phenotypes through mechanisms ultimately resulting from integrating their preexisting history and surrounding environmental signals to enable a distinct transcriptional program. In addition, their distinct transcriptional program must enable their phenotype to be distinct from other myeloid cells. The transcriptional program that makes them distinct is controlled via various epigenetic processes, among which include DNA methylation, histone modification and expression of noncoding RNAs. These epigenetic modifications of the landscape lead to either compaction or opening of the chromatin, followed by the combination of DNA and DNA-binding proteins, which are associated to gene activation or repression. This is the basis of trained immunity, a new concept in the field, which postulates that innate immune cells can retain a memory of certain primary stimuli via epigenetic mechanisms, thus potentially priming them to initiate a stronger response upon a secondary stimulus.

The term "epigenetics" was first pioneered by C.H. Waddington, seeking to explain how phenotypes could be explained not solely by genetic inheritance (157). He later then proposed the concept of the "epigenetic landscape," which posited that as cells differentiate, they become restricted in their possible fates (158). This concept of the epigenetic landscape was further elaborated on by Thomas Jenuwein and David Allis with their proposal of a "nucleosome code," an extension of the "histone code" $(159,160)$. In their "nucleosome code" hypothesis, they propose that certain covalent modifications to the tails of histones in a region of DNA ultimately result in regional compaction or opening of chromatin. How closed or opened the chromatin in a particular region is then ultimately governs the ability of DNAbinding proteins and ultimately RNA Polymerase from binding to certain genes and subsequently transcribing. The histone modifications that encourage opening of the chromatin include $\mathrm{H} 3 \mathrm{~K} 4 \mathrm{me} 3, \mathrm{H} 3 \mathrm{~K} 9 \mathrm{ac}$, and $\mathrm{H} 3 \mathrm{~K} 27 \mathrm{ac}$, weaken the grip tail of histone 3 (H3) to the DNA allowing other DNA-binding proteins to bind, while repressive histone modifications including $\mathrm{H} 3 \mathrm{~K} 9 \mathrm{me} 3$, $\mathrm{H} 3 \mathrm{~K} 27 \mathrm{me} 3$, and $\mathrm{H} 3 \mathrm{~K} 36 \mathrm{me} 3$ enhance the grip of $\mathrm{H} 3$ to the DNA promote the opposite effect. How protected the DNA is 
by chromatin opening or compaction, as a result of these histone modifications regionally, ultimately mediates the accessibility of RNA Polymerase to specific sites, thus governing gene activation or gene repression.

The link between an external stimulus to macrophages and modification of the epigenetic landscape, thus establishing the importance of the epigenome in macrophages, was first established in 1999, where LPS stimulation was shown to induce IL12 p40 production by the remodeling of nucleosomes positioned at its promoter (161). This process was later shown to be TLR-dependent via acetylation of residues on histone 3 and histone 4 typically associated with open chromatin. On a genome-wide level, TLR activation has been shown to induce a program where the "brakes" on inflammatory gene expression are withdrawn by removing repressive histone modifications. Specifically it was shown that the H3K27me3 demethylase JMJD3, is induced by LPS stimulation in macrophages, and thus promotes an inflammatory gene program (162). Conversely, histone modifications pertaining to gene activation, modifications that lessen the grip of nucleosomes on the DNA, are added on at specific loci upon LPS stimulation by various epigenetic writers including histone methyltransferase myeloid lymphoid leukemia (163). The fact that macrophages' epigenetic architecture is easily changeable upon external stimulation should not be surprising, given that large changes in histone methylation and acetylation patterns occur in the transition from monocytes to macrophages alone (29). In summary, these early studies made it clear that significant epigenetic changes were happening in macrophages.

Prior to stimulation to an exogenous substance, the epigenetic landscape of monocytes and macrophages must be properly established to develop their distinguished phenotype. This is done by the LDTFs (lineage-dependent transcription factor) PU.1 and the C/EBP family of transcription factors, which bind to macrophage-specific genes and enhancers and are critical for proper monocyte and macrophage development (164). These transcription factors are thought to prime these sites, including those of inflammatory genes, suggested by the fact that these loci are marked by the presence of PU.1, H3K4me1, and open chromatin. However, to keep the brakes on the expression of inflammatory genes, these same loci of inflammatory genes are decorated with repressive histone marks that promote chromatin compaction including $\mathrm{H} 3 \mathrm{~K} 9 \mathrm{me} 3$, $\mathrm{H} 3 \mathrm{~K} 27 \mathrm{me} 3$, and H4K20me3 and are bound by co-repressors (165-168). Only upon exogenous stimulation, these brakes are released by appropriate epigenetic erasers on the enhancers and promoters of inflammatory genes, and concurrently activating histone marks are added on by appropriate epigenetic writers.

Trained immunity is a relatively new compelling concept in immunology, whose foundation is primarily epigenetic based. It posits that innate immune cells can retain a memory after a primary stimulus and after a return to a resting phase enact a heightened response upon a secondary stimulus (169). The concept was first proposed in 2011 as a means to explain the phenomenon in vertebrates of protective effects of vaccinations or infections, including BCG vaccination and C. albicans infection, to unrelated stimuli in a manner independent of the adaptive immune system
(170). Soon after, the mechanisms underlying these memory phenomena were soon determined to be based on epigenetic and metabolic reprogramming, with the two being intertwined (29, 171-173). Specifically, significant H3K4me3 deposition upon either BCG vaccination or $ß$-glucan stimulation was found at the gene promoters of inflammatory genes including TNF- $\alpha$, IL- 6 and glycolysis genes including hexokinase and phosphofructokinase, thus establishing a memory in macrophages. This process was shown to be was mTOR-dependent $(172,173)$ and preventing epigenetic changes through the use of mTOR inhibitors, inhibited the shift in metabolism toward glycolysis and the acquisition of $\mathrm{H} 3 \mathrm{~K} 4 \mathrm{me} 3$ at key inflammatory gene promoters.

With regards to organ transplantation, Fadi Lakkis and colleagues described that monocytes are able to recall skin grafts exhibiting memory features normally attributed to adaptive immune cells. Using BALB/c Rag / ${ }^{-}$mice as recipients of BALB/ $\mathrm{c}\left(\mathrm{H}-2^{\mathrm{d}}\right)$, allogeneic $\mathrm{B} 6\left(\mathrm{H}-2^{\mathrm{b}}\right)$ and "third-party" $\mathrm{C} 3 \mathrm{H}\left(\mathrm{H}-2^{\mathrm{k}}\right)$ donor skin grafts rechallenged with B6 splenocytes 1 week after engraftment, the study demonstrated that monocytes were able to mount an inflammatory response 1 week after transplantation independently of the adaptive immune system (134). Interestingly, $\mathrm{BALB} / \mathrm{c}$ recipients mounted an allo-dependent response to allogeneic B6, but also to "third-party" C3H (134). Although the third-party response was statistically lower than the allo-dependent response, the data suggests that monocytes are able to respond to non-specific recall stimuli, a feature of trained immunity. Challenging the view of non-specific responses mediated by macrophages, studies from Xian $\mathrm{Li}$ and colleagues reported that reconstituted $\mathrm{Rag}^{-} /{ }^{-} \gamma \mathrm{c}^{-} /^{-}$hosts with syngeneic B6 CD4+ T cells and donor $\mathrm{BALB} / \mathrm{c}$ cells results in in vivo killing of donor $\mathrm{BALB} / \mathrm{c}$ cells transferred 2 weeks after reconstitution but does not result in the rejection of "third-party" C3H cells (174). This argues in favor of further investigating epigenetic mechanisms of macrophage recall processes and the potential implication of SIRP $\alpha$ in these processes, as described above. Remarkably, this study demonstrated that macrophage-mediated rejection of recall responses can be prevented with $\mathrm{CD} 40 / \mathrm{CD} 40 \mathrm{~L}$ costimulatory blockade during the first stimuli. This suggests that anti-CD40L $\mathrm{mAb}$ treatment may prevent the accumulation of memory-like macrophages in the donor allografts early after transplantation.

Inhibition of trained macrophages in the allograft can be achieved by targeting the mTOR pathway in myeloid cells in vivo (155). We recently demonstrated that vimentin promotes macrophage training via dectin-1 signaling, which results in increasing deposition of $\mathrm{H} 3 \mathrm{~K} 4 \mathrm{me} 3$ at the promoter of TNFalpha and IL-6 upon a secondary stimulation with HMGB1, another protein highly expressed in the donor allograft. The same trend in epigenetic changes occur in vivo using an experimental mouse model of heart transplantation. Interestingly, inhibition of trained immunity with mTORi-HDL nanobiologics promoted long-term allograft survival via Treg expansion and inhibition of cytotoxic T cells.

In addition to targeting trained immunity in organ transplantation via the administration of mTORi-HDL nanoparticles, there is the potential use of small molecules that inhibit epigenetic-related proteins including HDAC inhibitors (HDACi) and BET inhibitors (BETi). HDACi are thought to 
primarily inhibit histone deacetylation, thus promoting gene expression at specific loci, while BETi inhibit the binding of BET proteins to acetylated regions of the genome, which normally promote gene expression at specific loci (175). However, reports specifically implicating their use in the context of transplant have been few. In regards to the use of BET inhibitors, a synthetic compound, I-BET, was developed that was shown to repress gene expression of LPS-inducible genes in bone marrow derived macrophages (BMDM) ex-vivo (176). The importance of BET proteins in aiding gene expression of inflammatory genes in macrophages was established through use of $b r d 2$ lo mice and silencing of BET proteins through siRNA studies (177). With regards to the use of an HDACi to prevent allograft refection, an inhibitor of HDAC6, KA1010, was shown to reduce allograft skin rejection through mechanisms that involved reduction in CD4 T cells with an increase in the Treg population (178). The effect of HDACi on macrophages on the other-hand is not clear and invitro experiments on BMDM treated trichostatin A (TSA), a class I and II HDACi, displayed a phenotype favoring progenitor-like myeloid cells rather than differentiated macrophages. These macrophages displayed a mixed M1/M2 phenotype according to cytokine and chemokine secretion analysis, suggesting that treatment with HDACi alone may not be a suggestable mode of therapeutic treatment (179). On the contrary, a study by Thangavel and colleagues demonstrated that combinatorial treatment of TSA with 5-Aza 2-deoxycytidine (Aza), a DNA methyl transferase (DNMT) inhibitor, was able to promote an M2 phenotype in macrophages and to reduce inflammation in an acute lung injury model (180). Overall, while drugs targeting epigenetic modifiers including HDACs, BET proteins and DNMTs do hold promise as therapeutic approaches that promote long-tern allograft survival in organ transplantation, it appears that successful use of these drugs to prevent graft rejection will require their use to be in combination with other drugs.

\section{CONCLUDING REMARKS AND FUTURE PERSPECTIVES}

Organ transplantation is a life-saving strategy for terminal and irreversible organ failure. While the solid organ transplantation has achieved an excellent success in short-term graft survival rates, the long-term survival rates of organ transplants remain suboptimal. The pathophysiology of graft rejection is multifactorial and growing evidence suggests that macrophages are key mediators of acute and chronic graft loss, through the secretion of

\section{REFERENCES}

1. Colvin M, Smith JM, Hadley N, Skeans MA, Uccellini K, Goff R, et al. OPTN/SRTR 2018 Annual Data Report: Heart. Am J Transplant (2020) 20 (s1):340-426. doi: 10.1111/ajt.15676

2. Stegall MD, Gaston RS, Cosio FG, Matas A. Through a glass darkly: seeking clarity in preventing late kidney transplant failure. J Am Soc Nephrol JASN (2015) 26(1):20-9. doi: 10.1681/ASN.2014040378 inflammatory mediators that activate the adaptive alloimmune response. Historically, accumulation of macrophages in the donor organ has been associated with transplant rejection $(181,182)$ as allogeneic antigen-primed macrophages mediate allograft rejection (183). However, not all macrophages are associated with graft loss. Different subpopulations of macrophages regulate the allograft immune response through protective mechanisms based on their phenotype and function. As a result, the identification of the in vivo signaling pathways that govern macrophage polarization and modulate their function may provide new therapeutic targets that promote allograft survival.

Therapeutic agents that regulate macrophage polarization that promote the accumulation of regulatory macrophages are potential candidates to promote long-term allograft survival in transplant recipients. In addition, identification of previously unrecognized pathways associated with chronic allograft rejection may offer new therapeutic avenues for intervention. Classically, the innate immune response has been defined as a non-specific rapid response, followed by a later-onset of antigenspecific adaptive immune cells. However, accumulating findings have challenged the fact that innate immune cells do not possess a memory, leading to the concept of innate immune memory and trained immunity. This concept postulates that stimulated innate immune cells are primed to recognize specific ligands and secrete specific cytokines more rapidly upon a second stimulus. This type of memory is retained by mechanisms of epigenetic and metabolic changes in innate immune cells exposed to particular ligands. As a result, therapeutic targeting of trained immunity represents a novel treatment paradigm to prevent allograft rejection. Thus, a comprehensive understanding of the immunobiology of different macrophage subsets is crucial to develop novel strategies that promote long-term allograft survival in transplant recipients and to translate macrophagetargeted therapeutic strategies in the clinic.

\section{AUTHOR CONTRIBUTIONS}

All authors contributed to the article and approved the submitted version.

\section{FUNDING}

The authors' work is supported by National Institutes of Health grants R01 AI139623AI (JO), and NIH-T32CA078207 (FO).
3. Lodhi SA, Lamb KE, Meier-Kriesche HU. Solid Organ Allograft Survival Improvement in the United States: The Long-Term Does Not Mirror the Dramatic Short-Term Success. Am J Transplant (2011) 11(6):1226-35. doi: 10.1111/j.1600-6143.2011.03539.x

4. Hall BM, Dorsch S, Roser B. The cellular basis of allograft rejection in vivo. I. The cellular requirements for first-set rejection of heart grafts. $J$ Exp Med (1978) 148(4):878-89. doi: 10.1084/jem.148.4.878

5. Bradley JA, Sarawar SR, Porteous C, Wood PJ, Card S, Ager A, et al. Allograft rejection in $\mathrm{cd} 4+\mathrm{t}$ cell-reconstituted athymic nude rats-the 
nonessential role of hostderived cd8+ cells1. Transplantation (1992) 53 (2):477-82. doi: 10.1097/00007890-199202010-00040

6. Kuhn C, Weiner HL. Therapeutic anti-CD3 monoclonal antibodies: from bench to bedside. Immunotherapy (2016) 8(8):889-906. doi: 10.2217/imt2016-0049

7. Sánchez-Fueyo A, Whitehouse G, Grageda N, Cramp ME, Lim TY, Romano $\mathrm{M}$, et al. Applicability, safety, and biological activity of regulatory $\mathrm{T}$ cell therapy in liver transplantation. Am J Transplant (2020) 20(4):1125-36. doi: 10.1111/ajt.15700

8. Parsons RF, Larsen CP, Pearson TC, Badell IR. Belatacept and CD28 Costimulation Blockade: Preventing and Reducing Alloantibodies over the Long Term. Curr Transplant Rep (2019) 6(4):277-84. doi: 10.1007/s40472019-00260-3

9. Cobbold SP, Jayasuriya A, Nash A, Prospero TD, Waldmann H. Therapy with monoclonal antibodies by elimination of T-cell subsets in vivo. Nature (1984) 312(5994):548-51. doi: 10.1038/312548a0

10. Scully R, Qin S, Cobbold S, Waldmann H. Mechanisms in CD4 antibodymediated transplantation tolerance: kinetics of induction, antigen dependency and role of regulatory T cells. Eur J Immunol (1994) 24 (10):2383-92. doi: 10.1002/eji.1830241019

11. Hirsch R, Gress RE, Pluznik DH, Eckhaus M, Bluestone JA. Effects of in vivo administration of anti-CD3 monoclonal antibody on $\mathrm{T}$ cell function in mice. II. In vivo activation of T cells. J Immunol (1989) 142(3):737.

12. Alegre ML, Tso JY, Sattar HA, Smith J, Desalle F, Cole M, et al. An antimurine CD3 monoclonal antibody with a low affinity for Fc gamma receptors suppresses transplantation responses while minimizing acute toxicity and immunogenicity. J Immunol (1995) 155(3):1544.

13. Parker DC, Greiner DL, Phillips NE, Appel MC, Steele AW, Durie FH, et al. Survival of mouse pancreatic islet allografts in recipients treated with allogeneic small lymphocytes and antibody to CD40 ligand. Proc Natl Acad Sci (1995) 92(21):9560. doi: 10.1073/pnas.92.21.9560

14. Larsen CP, Elwood ET, Alexander DZ, Ritchie SC, Hendrix R, TuckerBurden C, et al. Long-term acceptance of skin and cardiac allografts after blocking CD40 and CD28 pathways. Nature (1996) 381(6581):434-8. doi: $10.1038 / 381434 \mathrm{a} 0$

15. Isobe $\mathrm{M}$, Yagita $\mathrm{H}$, Okumura $\mathrm{K}$, Ihara A. Specific acceptance of cardiac allograft after treatment with antibodies to ICAM-1 and LFA-1. Science (1992) 255(5048):1125. doi: 10.1126/science. 1347662

16. Chavin KD, Lau HT, Bromberg JS. Prolongation of allograft and xenograft survival in mice by anti-CD2 monoclonal antibodies. Transplantation (1992) 54(2):286-91. doi: 10.1097/00007890-199208000-00018

17. Kaplan AJ, Chavin KD, Yagita H, Sandrin MS, Qin LH, Lin J, et al. Production and characterization of soluble and transmembrane murine CD2. Demonstration that $\mathrm{CD} 48$ is a ligand for $\mathrm{CD} 2$ and that $\mathrm{CD} 48$ adhesion is regulated by CD2. J Immunol (1993) 151(8):4022.

18. Weaver TA, Charafeddine AH, Agarwal A, Turner AP, Russell M, Leopardi $\mathrm{FV}$, et al. Alefacept promotes co-stimulation blockade based allograft survival in nonhuman primates. Nat Med (2009) 15(7):746-9. doi: 10.1038/nm.1993

19. Hancock WW, Sayegh MH, Zheng X-G, Peach R, Linsley PS, Turka LA. Costimulatory function and expression of CD40 ligand, CD80, and CD86 in vascularized murine cardiac allograft rejection. Proc Natl Acad Sci (1996) 93 (24):13967. doi: 10.1073/pnas.93.24.13967

20. Fishbein TM, Wang L, Benjamin C, Liu J, Tarcsafalvi A, Leytin A, et al. Successful tolerance induction under CD40 ligation in a rodent small bowel transplant model: first report of a study with the novel antibody AH.F5. Transplantation (2002) 73(12):1943-8. doi: 10.1097/00007890-20020627000017

21. Lin H, Bolling SF, Linsley PS, Wei RQ, Gordon D, Thompson CB, et al. Long-term acceptance of major histocompatibility complex mismatched cardiac allografts induced by CTLA4Ig plus donor-specific transfusion. J Exp Med (1993) 178(5):1801-6. doi: 10.1084/jem.178.5.1801

22. Valenzuela NM, Reed EF. Antibody-mediated rejection across solid organ transplants: manifestations, mechanisms, and therapies. J Clin Invest (2017) 127(7):2492-504. doi: 10.1172/JCI90597

23. Venner JM, Famulski KS, Badr D, Hidalgo LG, Chang J, Halloran PF. Molecular Landscape of T Cell-Mediated Rejection in Human Kidney Transplants: Prominence of CTLA4 and PD Ligands. Am J Transplant (2014) 14(11):2565-76. doi: 10.1111/ajt.12946
24. Ochando J, Ordikhani F, Boros P, Jordan S. The innate immune response to allotransplants: mechanisms and therapeutic potentials. Cell Mol Immunol (2019) 16(4):350-6. doi: 10.1038/s41423-019-0216-2

25. Alegre M-L, Chong A. Toll-like receptors (TLRs) in transplantation. Front Biosci (Elite Ed) (2009) 1:36-43.

26. Ochando J, Kwan WH, Ginhoux F, Hutchinson JA, Hashimoto D, Collin M. The Mononuclear Phagocyte System in Organ Transplantation. Am J Transplant (2016) 16(4):1053-69. doi: 10.1111/ajt.13627

27. Leventhal JS, Schröppel B. Toll-like receptors in transplantation: sensing and reacting to injury. Kidney Int (2012) 81(9):826-32. doi: 10.1038/ ki.2011.498

28. Sheen J-H, Strainic MG, Liu J, Zhang W, Yi Z, Medof ME, et al. TLRInduced Murine Dendritic Cell (DC) Activation Requires DC-Intrinsic Complement. J Immunol (Baltimore Md 1950) (2017) 199(1):278-91. doi: 10.4049/jimmunol.1700339

29. Saeed S, Quintin J, Kerstens HHD, Rao NA, Aghajanirefah A, Matarese F, et al. Epigenetic programming of monocyte-to-macrophage differentiation and trained innate immunity. Science (2014) 345(6204):1251086. doi: 10.1126/science. 1251086

30. Netea MG, Joosten LAB, Latz E, Mills KHG, Natoli G, Stunnenberg HG, et al. Trained immunity: A program of innate immune memory in health and disease. Science (2016) 352(6284):aaf1098. doi: 10.1126/science.aaf1098

31. Sica A, Mantovani A. Macrophage plasticity and polarization: in vivo veritas. J Clin Invest (2012) 122(3):787-95. doi: 10.1172/JCI59643

32. Ginhoux F, Jung S. Monocytes and macrophages: developmental pathways and tissue homeostasis. Nat Rev Immunol (2014) 14:392. doi: 10.1038/ nri3671

33. Gordon S, Taylor PR. Monocyte and macrophage heterogeneity. Nat Rev Immunol (2005) 5:953. doi: 10.1038/nri1733

34. Mannon RB. Macrophages: contributors to allograft dysfunction, repair, or innocent bystanders? Curr Opin Organ Transplant (2012) 17(1):20-5. doi: 10.1097/MOT.0b013e32834ee5b6

35. Jakubzick CV, Randolph GJ, Henson PM. Monocyte differentiation and antigen-presenting functions. Nat Rev Immunol (2017) 17(6):349-62. doi: $10.1038 /$ nri.2017.28

36. Mills CD. M1 and M2 Macrophages: Oracles of Health and Disease. Crit Rev Immunol (2012) 32(6):463-88. doi: 10.1615/critrevimmunol.v32.16.10

37. Mills CD, Kincaid K, Alt JM, Heilman MJ, Hill AM. M-1/M-2 Macrophages and the Th1/Th2 Paradigm. J Immunol (2000) 164(12):6166-73. doi: 10.4049/jimmunol.164.12.6166

38. Pesce JT, Ramalingam TR, Mentink-Kane MM, Wilson MS, El Kasmi KC, Smith AM, et al. Arginase-1-expressing macrophages suppress Th2 cytokine-driven inflammation and fibrosis. PLoS Pathog (2009) 5(4): e1000371. doi: 10.1371/journal.ppat.1000371

39. MacMicking J, Xie Q-W, Nathan C. Nitric oxide and macrphage function. Annu Rev Immunol (1997) 15(1):323-50. doi: 10.1146/annurev.immunol. 15.1 .323

40. Van den Bossche J, Lamers WH, Koehler ES, Geuns JM, Alhonen L, Uimari A, et al. Pivotal Advance: Arginase-1-independent polyamine production stimulates the expression of IL-4-induced alternatively activated macrophage markers while inhibiting LPS-induced expression of inflammatory genes. J Leukoc Biol (2012) 91(5):685-99. doi: 10.1189/ jlb.0911453

41. Mosser DM, Edwards JP. Exploring the full spectrum of macrophage activation. Nat Rev Immunol (2008) 8(12):958-69. doi: 10.1038/nri2448

42. Mantovani A, Sozzani S, Locati M, Allavena P, Sica A. Macrophage polarization: tumor-associated macrophages as a paradigm for polarized M2 mononuclear phagocytes. Trends Immunol (2002) 23(11):549-55. doi: 10.1016/S1471-4906(02)02302-5

43. Nathan CF, Murray HW, Wiebe ME, Rubin BY. Identification of interferongamma as the lymphokine that activates human macrophage oxidative metabolism and antimicrobial activity. J Exp Med (1983) 158(3):670-89. doi: $10.1084 /$ jem.158.3.670

44. Glass CK, Natoli G. Molecular control of activation and priming in macrophages. Nat Immunol (2016) 17(1):26-33. doi: 10.1038/ni.3306

45. Wendel M, Galani IE, Suri-Payer E, Cerwenka A. Natural killer cell accumulation in tumors is dependent on IFN-gamma and CXCR3 ligands. Cancer Res (2008) 68(20):8437-45. doi: 10.1158/0008-5472.Can-08-1440 
46. Hensbergen PJ, Wijnands PG, Schreurs MW, Scheper RJ, Willemze R, Tensen CP. The CXCR3 Targeting Chemokine CXCL11 Has Potent Antitumor Activity In Vivo Involving Attraction of CD8+ T Lymphocytes But Not Inhibition of Angiogenesis. J Immunother (2005) 28(4):343-51. doi: 10.1097/01.cji.0000165355.26795.27

47. Donlin LT, Jayatilleke A, Giannopoulou EG, Kalliolias GD, Ivashkiv LB. Modulation of TNF-Induced Macrophage Polarization by Synovial Fibroblasts. J Immunol (2014) 193(5):2373-83. doi: 10.4049/ jimmunol.1400486

48. Hsieh G. Listeria induced TH1 development in $\alpha \beta T C R$ transgenic CD4_+ T cells occurs through macrophage production of IL-12. Science (1992) 260:547-9. doi: 10.1126/science.8097338

49. Szabo SJ, Kim ST, Costa GL, Zhang X, Fathman CG, Glimcher LH. A novel transcription factor, T-bet, directs Th1 lineage commitment. Cell (2000) 100 (6):655-69. doi: 10.1016/S0092-8674(00)80702-3

50. Szabo SJ, Sullivan BM, Peng SL, Glimcher LH. Molecular mechanisms regulating Th1 immune responses. Annu Rev Immunol (2003) 21:713-58. doi: 10.1146/annurev.immunol.21.120601.140942

51. Lighvani AA, Frucht DM, Jankovic D, Yamane H, Aliberti J, Hissong BD, et al. T-bet is rapidly induced by interferon-gamma in lymphoid and myeloid cells. Proc Natl Acad Sci U S A (2001) 98(26):15137-42. doi: $10.1073 /$ pnas. 261570598

52. Zhou L, Ivanov III, Spolski R, Min R, Shenderov K, Egawa T, et al. IL-6 programs TH-17 cell differentiation by promoting sequential engagement of the IL-21 and IL-23 pathways. Nat Immunol (2007) 8(9):967-74. doi: $10.1038 /$ ni1 488

53. Korn T, Bettelli E, Oukka M, Kuchroo VK. IL-17 and Th17 Cells. Annu Rev Immunol (2009) 27(1):485-517. doi: 10.1146/annurev.immunol.021908.132710

54. Aggarwal S, Ghilardi N, Xie MH, de Sauvage FJ, Gurney AL. Interleukin-23 promotes a distinct $\mathrm{CD} 4 \mathrm{~T}$ cell activation state characterized by the production of interleukin-17. J Biol Chem (2003) 278(3):1910-4. doi: 10.1074/jbc.M207577200

55. Ley K, Gerdes N, Winkels H. ATVB Distinguished Scientist Award. Arteriosclerosis Thrombosis Vasc Biol (2017) 37(5):764-77. doi: 10.1161/ ATVBAHA.117.308611

56. Subauste CS, de Waal Malefyt R, Fuh F. Role of CD80 (B7.1) and CD86 (B7.2) in the immune response to an intracellular pathogen. J Immunol (1998) 160(4):1831-40.

57. Elgueta R, Benson MJ, de Vries VC, Wasiuk A, Guo Y, Noelle RJ. Molecular mechanism and function of $\mathrm{CD} 40 / \mathrm{CD} 40 \mathrm{~L}$ engagement in the immune system. Immunol Rev (2009) 229(1):152-72. doi: 10.1111/j.1600065X.2009.00782.x

58. Mantovani A, Sica A, Sozzani S, Allavena P, Vecchi A, Locati M. The chemokine system in diverse forms of macrophage activation and polarization. Trends Immunol (2004) 25(12):677-86. doi: 10.1016/ j.it.2004.09.015

59. Rőszer T. Understanding the Mysterious M2 Macrophage through Activation Markers and Effector Mechanisms. Mediators Inflammation (2015) 2015:816460. doi: 10.1155/2015/816460

60. Colin S, Chinetti-Gbaguidi G, Staels B. Macrophage phenotypes in atherosclerosis. Immunol Rev (2014) 262(1):153-66. doi: 10.1111/imr.12218

61. De Paoli F, Staels B, Chinetti-Gbaguidi G. Macrophage phenotypes and their modulation in atherosclerosis. Circ J (2014) 78(8):1775-81. doi: 10.1253/ circj.cj-14-0621

62. Wynn TA, Vannella KM. Macrophages in Tissue Repair, Regeneration, and Fibrosis. Immunity (2016) 44(3):450-62. doi: 10.1016/j.immuni.2016.02.015

63. Yue Y, Yang X, Feng K, Wang L, Hou J, Mei B, et al. M2b macrophages reduce early reperfusion injury after myocardial ischemia in mice: A predominant role of inhibiting apoptosis via A20. Int J Cardiol (2017) 245:228-35. doi: 10.1016/j.ijcard.2017.07.085

64. Ambarus CA, Santegoets KCM, van Bon L, Wenink MH, Tak PP, Radstake TRDJ, et al. Soluble Immune Complexes Shift the TLR-Induced Cytokine Production of Distinct Polarized Human Macrophage Subsets towards IL10. PLoS One (2012) 7(4):e35994. doi: 10.1371/journal.pone.0035994

65. Zizzo G, Hilliard BA, Monestier M, Cohen PL. Efficient clearance of early apoptotic cells by human macrophages requires M2c polarization and MerTK induction. J Immunol (2012) 189(7):3508-20. doi: 10.4049/ jimmunol.1200662
66. Duluc D, Delneste Y, Tan F, Moles MP, Grimaud L, Lenoir J, et al. Tumorassociated leukemia inhibitory factor and IL-6 skew monocyte differentiation into tumor-associated macrophage-like cells. Blood (2007) 110(13):4319-30. doi: 10.1182/blood-2007-02-072587

67. Wang Y, Tian J, Tang X, Rui K, Tian X, Ma J, et al. Exosomes released by granulocytic myeloid-derived suppressor cells attenuate DSS-induced colitis in mice. Oncotarget (2016) 7(13):15356-68. doi: 10.18632/oncotarget.7324

68. Wang Q, Ni H, Lan L, Wei X, Xiang R, Wang Y. Fra-1 protooncogene regulates IL- 6 expression in macrophages and promotes the generation of M2d macrophages. Cell Res (2010) 20(6):701-12. doi: 10.1038/cr.2010.52

69. Wu H, Xu JB, He YL, Peng JJ, Zhang XH, Chen CQ, et al. Tumor-associated macrophages promote angiogenesis and lymphangiogenesis of gastric cancer. J Surg Oncol (2012) 106(4):462-8. doi: 10.1002/jso.23110

70. Anderson CF, Mosser DM. A novel phenotype for an activated macrophage: the type 2 activated macrophage. J Leukoc Biol (2002) 72(1):101-6.

71. Jablonski KA, Amici SA, Webb LM, Ruiz-Rosado Jde D, Popovich PG. S. Partida-Sanchez and M. Guerau-de-Arellano: Novel Markers to Delineate Murine M1 and M2 Macrophages. PLoS One (2015) 10(12):e0145342. doi: 10.1371/journal.pone.0145342

72. Buscher K, Ehinger E, Gupta P, Pramod AB, Wolf D, Tweet G, et al. Natural variation of macrophage activation as disease-relevant phenotype predictive of inflammation and cancer survival. Nat Commun (2017) 8:16041. doi: 10.1038/ncomms 16041

73. Porta C, Rimoldi M, Raes G, Brys L, Ghezzi P, Di Liberto D, et al. Tolerance and M2 (alternative) macrophage polarization are related processes orchestrated by p50 nuclear factor KB. Proc Natl Acad Sci (2009) 106 (35):14978-83. doi: 10.1073/pnas.0809784106

74. Mokarram N, Bellamkonda RV. A perspective on immunomodulation and tissue repair. Ann BioMed Eng (2014) 42(2):338-51. doi: 10.1007/s10439013-0941-0

75. Mantovani A, Biswas SK, Galdiero MR, Sica A, Locati M. Macrophage plasticity and polarization in tissue repair and remodelling. J Pathol (2013) 229(2):176-85. doi: 10.1002/path.4133

76. Kobayashi T, Matsuoka K, Sheikh SZ, Elloumi HZ, Kamada N, Hisamatsu T, et al. NFIL3 is a regulator of IL-12 p40 in macrophages and mucosal immunity. J Immunol (Baltimore Md 1950) (2011) 186(8):4649-55. doi: $10.4049 /$ jimmunol.1003888

77. Lin CC, Bradstreet TR, Schwarzkopf EA, Sim J, Carrero JA, Chou C, et al. Bhlhe40 controls cytokine production by $\mathrm{T}$ cells and is essential for pathogenicity in autoimmune neuroinflammation. Nat Commun (2014) 5:3551. doi: $10.1038 /$ ncomms 4551

78. Feinberg MW, Cao Z, Wara AK, Lebedeva MA, Senbanerjee S, Jain MK. Kruppel-like factor 4 is a mediator of proinflammatory signaling in macrophages. J Biol Chem (2005) 280(46):38247-58. doi: 10.1074/ jbc.m509378200

79. Orecchioni M, Ghosheh Y, Pramod AB, Ley K. Macrophage Polarization: Different Gene Signatures in M1(LPS+) vs. Classically and M2(LPS-) vs. Alternatively Activated Macrophages. Front Immunol (2019) 10:1084. doi: 10.3389/fimmu.2019.01084

80. Müller E, Christopoulos PF, Halder S, Lunde A, Beraki K, Speth M, et al. TollLike Receptor Ligands and Interferon- $\gamma$ Synergize for Induction of Antitumor M1 Macrophages. Front Immunol (2017) 8:1383. doi: 10.3389/fimmu.2017.01383

81. Müller E, Speth M, Christopoulos PF, Lunde A, Avdagic A, Øynebråten I, et al. and Type II Interferons Can Activate Antitumor M1 Macrophages When Combined With TLR Stimulation. Front Immunol (2018) 9:2520. doi: $10.3389 /$ fimmu.2018.02520

82. Zhang L, Dong Y, Dong Y, Cheng J, Du J. Role of integrin- $\beta 3$ protein in macrophage polarization and regeneration of injured muscle. J Biol Chem (2012) 287(9):6177-86. doi: 10.1074/jbc.M111.292649

83. Pallett LJ, Burton AR, Amin OE, Rodriguez-Tajes S, Patel AA, Zakeri N, et al. Longevity and replenishment of human liver-resident memory $\mathrm{T}$ cells and mononuclear phagocytes. J Exp Med (2020) 217(9):1-11. doi: 10.1084/ jem.20200050

84. Perdiguero EG, Geissmann F. The development and maintenance of resident macrophages. Nat Immunol (2016) 17(1):2-8. doi: 10.1038/ni.3341

85. Li J, Li C, Zhuang Q, Peng B, Zhu Y, Ye Q, et al. The Evolving Roles of Macrophages in Organ Transplantation. J Immunol Res (2019) 2019:5763430. doi: 10.1155/2019/5763430 
86. Ginhoux F, Schultze JL, Murray PJ, Ochando J, Biswas SK. New insights into the multidimensional concept of macrophage ontogeny, activation and function. Nat Immunol (2016) 17(1):34-40. doi: 10.1038/ni.3324

87. Sato K, Yabuki K, Haba T, Maekawa T. Role of Kupffer cells in the induction of tolerance after liver transplantation. J Surg Res (1996) 63(2):433-8. doi: 10.1006/jsre.1996.0288

88. Ju C, McCoy JP, Chung CJ, Graf ML, Pohl LR. Tolerogenic role of Kupffer cells in allergic reactions. Chem Res Toxicol (2003) 16(12):1514-9. doi: $10.1021 /$ tx0341761

89. Soroosh P, Doherty TA, Duan W, Mehta AK, Choi H, Adams YF, et al. Lung-resident tissue macrophages generate Foxp3+ regulatory $\mathrm{T}$ cells and promote airway tolerance. J Exp Med (2013) 210(4):775-88. doi: 10.1084/ jem.20121849

90. Thornley TB, Fang Z, Balasubramanian S, Larocca RA, Gong W, Gupta S, et al. Fragile TIM-4-expressing tissue resident macrophages are migratory and immunoregulatory. J Clin Invest (2014) 124(8):3443-54. doi: 10.1172/ JCI73527

91. Powers KA, Szaszi K, Khadaroo RG, Tawadros PS, Marshall JC, Kapus A, et al. Oxidative stress generated by hemorrhagic shock recruits Toll-like receptor 4 to the plasma membrane in macrophages. J Exp Med (2006) 203 (8):1951-61. doi: 10.1084/jem.20060943

92. Prakash A, Sundar SV, Zhu YG, Tran A, Lee JW, Lowell C, et al. Lung Ischemia-Reperfusion is a Sterile Inflammatory Process Influenced by Commensal Microbiota in Mice. Shock (2015) 44(3):272-9. doi: 10.1097/ SHK.0000000000000415

93. Akbarpour M, Lecuona E, Chiu SF, Wu Q, Querrey M, Fernandez R, et al. Residual endotoxin induces primary graft dysfunction through ischemia/ reperfusion-primed alveolar macrophages. J Clin Invest (2020) 130(8):445669. doi: 10.1172/JCI135838

94. Holt PG. Alveolar macrophages. III. Studies on the mechanisms of inhibition of T-cell proliferation. Immunology (1979) 37(2):437-45.

95. Bilyk N, Holt PG. Inhibition of the immunosuppressive activity of resident pulmonary alveolar macrophages by granulocyte/macrophage colonystimulating factor. J Exp Med (1993) 177(6):1773-7. doi: 10.1084/ jem.177.6.1773

96. Poulter LW, Bradley NJ, Turk JL. The role of macrophages in skin allograft rejection: I. histochemical studies during first-set rejection.Transplantation (1971) 12(1):40-4. doi: 10.1097/00007890-197107000-00006

97. Tinckam KJ, Djurdjev O, Magil AB. Glomerular monocytes predict worse outcomes after acute renal allograft rejection independent of $\mathrm{C} 4 \mathrm{~d}$ status. Kidney Int (2005) 68(4):1866-74. doi: 10.1111/j.1523-1755.2005.00606.x

98. Hoshinaga K, Mohanakumar T, Goldman MH, Wolfgang TC, Szentpetery S, Lee HM, et al. Clinical significance of in situ detection of $\mathrm{T}$ lymphocyte subsets and monocyte/macrophage lineages in heart allografts. Transplantation (1984) 38(6):634-7. doi: 10.1097/00007890-19841200000017

99. Girlanda R, Kleiner DE, Duan Z, Ford EA, Wright EC, Mannon RB, et al. Monocyte infiltration and kidney allograft dysfunction during acute rejection. Am J Transplant (2008) 8(3):600-7. doi: 10.1111/j.16006143.2007.02109.x

100. Hancock WW, Thomson NM, Atkins RC. Composition of interstitial cellular infiltrate identified by monoclonal antibodies in renal biopsies of rejecting human renal allografts. Transplantation (1983) 35(5):458-63. doi: 10.1097/ 00007890-198305000-00013

101. McLean AG, Hughes D, Welsh KII, Gray DW, Roake J, Fuggle SV, et al. Patterns of graft infiltration and cytokine gene expression during the first 10 days of kidney transplantation. Transplantation (1997) 63(3):374-80. doi: 10.1097/00007890-199702150-00008

102. Raftery MJ, Seron D, Koffman G, Hartley B, Janossy G, Cameron JS. The relevance of induced class II HLA antigens and macrophage infiltration in early renal allograft biopsies. Transplantation (1989) 48(2):238-43. doi: 10.1097/00007890-198908000-00011

103. Qi F, Adair A, Ferenbach D, Vass DG, Mylonas KJ, Kipari T, et al. Depletion of Cells of Monocyte Lineage Prevents Loss of Renal Microvasculature in Murine Kidney Transplantation. Transplantation (2008) 86(9):1267-74. doi: 10.1097/TP.0b013e318188d433

104. Wu YL, Ye Q, Eytan DF, Liu L, Rosario BL, Hitchens TK, et al. Magnetic resonance imaging investigation of macrophages in acute cardiac allograft rejection after heart transplantation. Circ Cardiovasc Imaging (2013) 6 (6):965-73. doi: 10.1161/CIRCIMAGING.113.000674

105. Jose MD, Ikezumi Y, van Rooijen N, Atkins RC, Chadban SJ. Macrophages act as effectors of tissue damage in acute renal allograft rejection. Transplantation (2003) 76(7):1015-22. doi: 10.1097/01.Tp.0000083507.67995.13

106. Ma FY, Woodman N, Mulley WR, Kanellis J, Nikolic-Paterson DJ. Macrophages Contribute to Cellular But Not Humoral Mechanisms of Acute Rejection in Rat Renal Allografts. Transplantation (2013) 96 (11):949-57. doi: 10.1097/TP.0b013e3182a4befa

107. Garcia MR, Ledgerwood L, Yang Y, Xu J, Lal G, Burrell B, et al. Monocytic suppressive cells mediate cardiovascular transplantation tolerance in mice. J Clin Invest (2010) 120(7):2486-96. doi: 10.1172/JCI41628

108. Conde P, Rodriguez M, van der Touw W, Jimenez A, Burns M, Miller J, et al. DC-SIGN+ Macrophages Control the Induction of Transplantation Tolerance. Immunity (2015) 42(6):1143-58. doi: 10.1016/j.immuni.2015. 05.009

109. van den Bosch TPP, Caliskan K, Kraaij MD, Constantinescu AA, Manintveld OC, Leenen PJM, et al. CD16+ Monocytes and Skewed Macrophage Polarization toward M2 Type Hallmark Heart Transplant Acute Cellular Rejection. Front Immunol (2017) 8(346):1-11. doi: 10.3389/ fimmu.2017.00346

110. Toki D, Zhang W, Hor KLM, Liuwantara D, Alexander SII, Yi Z, et al. The Role of Macrophages in the Development of Human Renal Allograft Fibrosis in the First Year After Transplantation. Am J Transplant (2014) 14(9):212636. doi: 10.1111/ajt.12803

111. Deng J, Zhou B, Lin B, Geng L, Shen T, Shu R, et al. Prediction of CD16+ Monocyte in Acute Rejection after Liver Transplantation. Ann Clin Lab Sci (2018) 48(3):328-32.

112. Azad TD, Donato M, Heylen L, Liu AB, Shen-Orr SS, Sweeney TE, et al. Inflammatory macrophage-associated 3-gene signature predicts subclinical allograft injury and graft survival. JCI Insight (2018) 3(2):1-12. doi: 10.1172/ jci.insight.95659

113. Singh KA, Kampen RL, Hoffmann SC, Eldaif SM, Kirk AD. Renal epithelial cell-derived monocyte colony stimulating factor as a local informant of renal injury and means of monocyte activation. Transplant Int (2009) 22(7):730-7. doi: 10.1111/j.1432-2277.2009.00840.x

114. Salama M, Andrukhova O, Roedler S, Zuckermann A, Laufer G, Aharinejad S. Association of CD14+ monocyte-derived progenitor cells with cardiac allograft vasculopathy. J Thoracic Cardiovasc Surg (2011) 142(5):1246-53. doi: 10.1016/j.jtcvs.2011.07.032

115. Kloc M, Ghobrial RM. Chronic allograft rejection: A significant hurdle to transplant success. Burns Trauma (2014) 2(1):3-10. doi: 10.4103/23213868.121646

116. Field AC, Dai J, Louedec L, Patey N, Bloch MJ, et al. Lymphoid neogenesis in chronic rejection: evidence for a local humoral alloimmune response. Proc Natl Acad Sci U S A (2005) 102(41):14723-8. doi: 10.1073/pnas.0507223102

117. Libby P, Pober JS. Chronic Rejection. Immunity (2001) 14(4):387-97. doi: 10.1016/S1074-7613(01)00119-4

118. Kitchens W, Chase C, Uehara S, Cornell L, Colvin R, Russell P, et al Macrophage Depletion Suppresses Cardiac Allograft Vasculopathy in Mice. Am J Transplant Off J Am Soc Transplant Am Soc Transplant Surg (2008) 7:2675-82. doi: 10.1111/j.1600-6143.2007.01997.x

119. Ikezumi Y, Suzuki T, Yamada T, Hasegawa H, Kaneko U, Hara M, et al. Alternatively activated macrophages in the pathogenesis of chronic kidney allograft injury. Pediatr Nephrol (2015) 30(6):1007-17. doi: 10.1007/s00467014-3023-0

120. Hutchinson JA. Macrophages in Transplantation. Transplantation (2015) 99 (5):898-898. doi: 10.1097/TP.0000000000000739

121. Kim J, Choi SE, Lim BJ, Kim YS, Huh KH, Lee J, et al. Clinical Significance of Macrophage Polarization in Antibody-Mediated Rejection of Renal Allograft. Transplant Proc (2018) 50(4):1005-8. doi: 10.1016/ j.transproceed.2018.02.037

122. Mitchell RN. Graft Vascular Disease: Immune Response Meets the Vessel Wall. Annu Rev Pathol: Mech Dis (2009) 4(1):19-47. doi: 10.1146/ annurev.pathol.3.121806.151449

123. Liu X, Lu Y, Lian Y, Chen Z, Xia J, Meng L, et al. Macrophage Depletion Improves Chronic Rejection in Rats With Allograft Heart Transplantation. Transplant Proc (2020) 52(3):992-1000. doi: 10.1016/j.transproceed.2019.12.037 
124. Hoffmann U, Bergler T, Segerer S, Rümmele P, Krüger B, Banas MC, et al. Impact of chemokine receptor CX3CR1 in human renal allograft rejection. Transplant Immunol (2010) 23(4):204-8. doi: 10.1016/j.trim.2010.06.006

125. Hume DA, MacDonald KPA. Therapeutic applications of macrophage colony-stimulating factor-1 (CSF-1) and antagonists of CSF-1 receptor (CSF-1R) signaling. Blood (2012) 119(8):1810-20. doi: 10.1182/blood2011-09-379214

126. Parihar A, Eubank TD, Doseff AII. Monocytes and macrophages regulate immunity through dynamic networks of survival and cell death. J Innate Immun (2010) 2(3):204-15. doi: 10.1159/000296507

127. Hamilton TA, Zhao C, Pavicic PG Jr., Datta S. Myeloid colony-stimulating factors as regulators of macrophage polarization. Front Immunol (2014) 5:554. doi: 10.3389/fimmu.2014.00554

128. Braza MS, Conde P, Garcia M, Cortegano I, Brahmachary M, Pothula V, et al. Neutrophil derived CSF1 induces macrophage polarization and promotes transplantation tolerance. Am J Transplant (2018) 18(5):124755. doi: 10.1111/ajt.14645

129. Zhao Y, Chen S, Lan P, Wu C, Dou Y, Xiao X, et al. Macrophage subpopulations and their impact on chronic allograft rejection versus graft acceptance in a mouse heart transplant model. Am J Transplant Off J Am Soc Transplant Am Soc Transplant Surg (2018) 18(3):604-16. doi: 10.1111/ ajt.14543

130. Wu C, Zhao Y, Xiao X, Fan Y, Kloc M, Liu W, et al. Graft-Infiltrating Macrophages Adopt an M2 Phenotype and Are Inhibited by Purinergic Receptor P2X7 Antagonist in Chronic Rejection. Am J Transplant Off J Am Soc Transplant Am Soc Transplant Surg (2016) 16(9):2563-73. doi: 10.1111/ ajt. 13808

131. Chen W, Chen S, Chen W, Li XC, Ghobrial RM, Kloc M. Screening RhoA/ ROCK inhibitors for the ability to prevent chronic rejection of mouse cardiac allografts. Transplant Immunol (2018) 50:15-25. doi: 10.1016/ j.trim.2018.06.002

132. Liu Y, Chen W, Wu C, Minze LJ, Kubiak JZ, Li XC, et al. Macrophage/ monocyte-specific deletion of Ras homolog gene family member A (RhoA) downregulates fractalkine receptor and inhibits chronic rejection of mouse cardiac allografts. J Heart Lung Transplant Off Publ Int Soc Heart Transplant (2017) 36(3):340-54. doi: 10.1016/j.healun.2016.08.011

133. Wang Y-Y, Jiang H, Pan J, Huang X-R, Wang Y-C, Huang H-F, et al. Macrophage-to-Myofibroblast Transition Contributes to Interstitial Fibrosis in Chronic Renal Allograft Injury. J Am Soc Nephrol JASN (2017) 28 (7):2053-67. doi: 10.1681/ASN.2016050573

134. Zecher D, van Rooijen N, Rothstein DM, Shlomchik WD, Lakkis FG. An innate response to allogeneic nonself mediated by monocytes. J Immunol (2009) 183(12):7810-6. doi: 10.4049/jimmunol.0902194

135. Dai H, Friday AJ, Abou-Daya KII, Williams AL, Mortin-Toth S, Nicotra ML, et al. Donor SIRP $\alpha$ polymorphism modulates the innate immune response to allogeneic grafts. Sci Immunol (2017) 2(12):eaam6202. doi: 10.1126/ sciimmunol.aam6202

136. Barclay AN. Signal regulatory protein alpha (SIRPalpha)/CD47 interaction and function. Curr Opin Immunol (2009) 21(1):47-52. doi: 10.1016/ j.coi. 2009.01 .008

137. Dugast A-S, Haudebourg T, Coulon F, Heslan M, Haspot F, Poirier N, et al. Myeloid-Derived Suppressor Cells Accumulate in Kidney Allograft Tolerance and Specifically Suppress Effector T Cell Expansion. J Immunol (2008) 180(12):7898-906. doi: 10.4049/jimmunol.180.12.7898

138. Chen Y-P, Kim HJ, Wu H, Price-Troska T, Villasboas JC, Jalali S, et al. SIRP $\alpha$ expression delineates subsets of intratumoral monocyte/macrophages with different functional and prognostic impact in follicular lymphoma. Blood Cancer J (2019) 9(10):84. doi: 10.1038/s41408-019-0246-0

139. Lakkis FG, Li XC. Innate allorecognition by monocytic cells and its role in graft rejection. Am J Transplant (2018) 18(2):289-92. doi: 10.1111/ ajt. 14436

140. Liu X, Kwon H, Li Z, Fu Y-X. Is CD47 an innate immune checkpoint for tumor evasion? J Hematol Oncol (2017) 10(1):12-2. doi: 10.1186/s13045016-0381-Z

141. Pengam S, Durand J, Usal C, Gauttier V, Dilek N, Martinet B, et al. SIRP $\alpha /$ CD47 axis controls the maintenance of transplant tolerance sustained by myeloid-derived suppressor cells. Am J Transplant (2019) 19(12):3263-75. doi: $10.1111 /$ ajt.15497
142. Dai H, Lan P, Zhao D, Abou-Daya K, Liu W, Chen W, et al. PIRs mediate innate myeloid cell memory to nonself MHC molecules. Science (2020) 368 (6495):1122. doi: 10.1126/science.aax 4040

143. Li L, Okusa MD. Macrophages, dendritic cells, and kidney ischemiareperfusion injury. Semin Nephrol (2010) 30(3):268-77. doi: 10.1016/ j.semnephrol.2010.03.005

144. Magil AB. Monocytes/macrophages in renal allograft rejection. Transplant Rev (Orlando) (2009) 23(4):199-208. doi: 10.1016/j.trre.2009.06.005

145. Broichhausen C, Riquelme P, Geissler EK, Hutchinson JA. Regulatory macrophages as therapeutic targets and therapeutic agents in solid organ transplantation. Curr Opin Organ Transplant (2012) 17(4):332-42. doi: 10.1097/MOT.0b013e328355a979

146. Fleming BD, Mosser DM. Regulatory macrophages: setting the threshold for therapy. Eur J Immunol (2011) 41(9):2498-502. doi: 10.1002/eji.201141717

147. Riquelme P, Tomiuk S, Kammler A, Fändrich F, Schlitt H, Geissler E, et al. IFN-induced iNOS Expression in Mouse Regulatory Macrophages Prolongs Allograft Survival in Fully Immunocompetent Recipients. Mol Ther (2013) 21(2):409-22. doi: 10.1038/mt.2012.168

148. Riquelme P, Hutchinson JA. Novel molecules mediate specialized functions of human regulatory macrophages. Curr Opin Organ Transplant (2018) 23 (5):533-7. doi: 10.1097/MOT.0000000000000560

149. Riquelme P, Haarer J, Kammler A, Walter L, Tomiuk S, Ahrens N, et al. TIGIT+ iTregs elicited by human regulatory macrophages control $\mathrm{T}$ cell immunity. Nat Commun (2018) 9(1):1-18. doi: 10.1038/s41467-018-05167-8

150. Hutchinson JA, Riquelme P, Geissler EK, Fandrich F. Human regulatory macrophages. Methods Mol Biol (2011) 677:181-92. doi: 10.1007/978-160761-869-0_13

151. Sawitzki B, Harden PN, Reinke P, Moreau A, Hutchinson JA, Game DS, et al. Regulatory cell therapy in kidney transplantation (The ONE Study): a harmonised design and analysis of seven non-randomised, single-arm, phase $1 / 2 \mathrm{~A}$ trials. Lancet (2020) 395(10237):1627-39. doi: 10.1016/S0140-6736(20)30167-7

152. Hutchinson JA, Ahrens N, Geissler EK. MITAP-compliant characterization of human regulatory macrophages. Transpl Int (2017) 30(8):765-75. doi: $10.1111 /$ tri. 12988

153. Ochando J, Braza MS. Nanoparticle-Based Modulation and Monitoring of Antigen-Presenting Cells in Organ Transplantation. Front Immunol (2017) 8:1888. doi: 10.3389/fimmu.2017.01888

154. Shirali AC, Look M, Du W, Kassis E, Stout-Delgado HW, Fahmy TM, et al. Nanoparticle Delivery of Mycophenolic Acid Upregulates PD-L1 on Dendritic Cells to Prolong Murine Allograft Survival. Am J Transplant (2011) 11(12):2582-92. doi: 10.1111/j.1600-6143.2011.03725.x

155. Braza MS, van Leent MMT, Lameijer M, Sanchez-Gaytan BL, Arts RJW, Pérez-Medina C, et al. Inhibiting Inflammation with Myeloid Cell-Specific Nanobiologics Promotes Organ Transplant Acceptance. Immunity (2018) 49 (5):819-28.e6. doi: 10.1016/j.immuni.2018.09.008

156. Patel K, Atkinson C, Tran D, Nadig SN. Nanotechnological Approaches to Immunosuppression and Tolerance Induction. Curr Transplant Rep (2017) 4 (2):159-68. doi: 10.1007/s40472-017-0146-9

157. Waddington C. The epigenotype. Int J Epidemiol (2012) 41(1):10-3. doi: $10.1093 / \mathrm{ije} / \mathrm{dyr} 184$

158. Waddington CH. The strategy of the Genes. London: Routledge (2014). pp. 28-30. doi: 10.4324/9781315765471

159. Jenuwein T, Allis CD. Translating the histone code. Science (2001) 293 (5532):1074-80. doi: 10.1126/science. 1063127

160. Strahl BD, Allis CD. The language of covalent histone modifications. Nature (2000) 403(6765):41-5. doi: 10.1038/47412

161. Weinmann AS, Plevy SE, Smale ST. Rapid and selective remodeling of a positioned nucleosome during the induction of IL-12 p40 transcription. Immunity (1999) 11(6):665-75. doi: 10.1016/s1074-7613(00)80141-7

162. De Santa F, Narang V, Yap ZH, Tusi BK, Burgold T, Austenaa L, et al. Jmjd3 contributes to the control of gene expression in LPS-activated macrophages. EMBO J (2009) 28(21):3341-52. doi: 10.1038/emboj.2009.271

163. Kittan NA, Allen RM, Dhaliwal A, Cavassani KA, Schaller M, Gallagher KA, et al. Cytokine induced phenotypic and epigenetic signatures are key to establishing specific macrophage phenotypes. PLoS One (2013) 8(10):e78045. doi: 10.1371/journal.pone.0078045

164. Heinz S, Benner C, Spann N, Bertolino E, Lin YC, Laslo P, et al. Simple combinations of lineage-determining transcription factors prime 
cis-regulatory elements required for macrophage and B cell identities. Mol Cell (2010) 38(4):576-89. doi: 10.1016/j.molcel.2010.05.004

165. Zhu Y, van Essen D, Saccani S. Cell-type-specific control of enhancer activity by H3K9 trimethylation. Mol Cell (2012) 46(4):408-23. doi: 10.1016/ j.molcel.2012.05.011

166. Kruidenier L, Chung CW, Cheng Z, Liddle J, Che K, Joberty G, et al. A selective jumonji H3K27 demethylase inhibitor modulates the proinflammatory macrophage response. Nature (2012) 488(7411):404-8. doi: 10.1038/nature11262

167. Stender JD, Pascual G, Liu W, Kaikkonen MU, Do K, Spann NJ, et al. Control of proinflammatory gene programs by regulated trimethylation and demethylation of histone H4K20. Mol Cell (2012) 48(1):28-38. doi: 10.1016/j.molcel.2012.07.020

168. Barish GD, Yu RT, Karunasiri M, Ocampo CB, Dixon J, Benner C, et al. Bcl-6 and NF-kappaB cistromes mediate opposing regulation of the innate immune response. Genes Dev (2010) 24(24):2760-5. doi: 10.1101/ gad.1998010

169. Netea MG, Domínguez-Andrés J, Barreiro LB, Chavakis T, Divangahi M, Fuchs E, et al. Defining trained immunity and its role in health and disease. Nat Rev Immunol (2020) 20(6):375-88. doi: 10.1038/s41577-020-0285-6

170. Netea MG, Quintin J, van der Meer JW. Trained immunity: a memory for innate host defense. Cell Host Microbe (2011) 9(5):355-61. doi: 10.1016/ j.chom.2011.04.006

171. Quintin J, Saeed S, Martens JH, Giamarellos-Bourboulis EJ, Ifrim DC, Logie $\mathrm{C}$, et al. Candida albicans infection affords protection against reinfection via functional reprogramming of monocytes. Cell Host Microbe (2012) 12 (2):223-32. doi: 10.1016/j.chom.2012.06.006

172. Cheng S-C, Quintin J, Cramer RA, Shepardson KM, Saeed S, Kumar V, et al. mTOR- and HIF-1 $\alpha$-mediated aerobic glycolysis as metabolic basis for trained immunity. Sci (N Y N.Y.) (2014) 345(6204):1250684-1250684. doi: $10.1126 /$ science. 1250684

173. Arts RJ, Novakovic B, Ter Horst R, Carvalho A, Bekkering S, Lachmandas E, et al. Glutaminolysis and Fumarate Accumulation Integrate Immunometabolic and Epigenetic Programs in Trained Immunity. Cell Metab (2016) 24(6):807-19. doi: 10.1016/j.cmet.2016.10.008

174. Liu W, Xiao X, Demirci G, Madsen J, Li XC. Innate NK Cells and Macrophages Recognize and Reject Allogeneic Nonself In Vivo via Different Mechanisms. J Immunol (2012) 188:2703-11. doi: 10.4049/ jimmunol.1102997

175. Suarez-Alvarez B, Rodriguez RM, Ruiz-Ortega M, Lopez-Larrea C. BET Proteins: An Approach to Future Therapies in Transplantation. Am J Transplant (2017) 17(9):2254-62. doi: 10.1111/ajt.14221
176. Nicodeme E, Jeffrey KL, Schaefer U, Beinke S, Dewell S, Chung CW, et al. Suppression of inflammation by a synthetic histone mimic. Nature (2010) 468(7327):1119-23. doi: 10.1038/nature09589

177. Belkina AC, Nikolajczyk BS, Denis GV. BET protein function is required for inflammation: Brd2 genetic disruption and BET inhibitor JQ1 impair mouse macrophage inflammatory responses. J Immunol (2013) 190(7):3670-8. doi: 10.4049/jimmunol.1202838

178. Ellis JD, Neil DA, Inston NG, Jenkinson E, Drayson MT, Hampson P, et al. Inhibition of Histone Deacetylase 6 Reveals a Potent Immunosuppressant Effect in Models of Transplantation. Transplantation (2016) 100(8):1667-74. doi: $10.1097 /$ tp.0000000000001208

179. Cabanel M, Brand C, Oliveira-Nunes MC, Cabral-Piccin MP, Lopes MF, Brito JM, et al. Epigenetic Control of Macrophage Shape Transition towards an Atypical Elongated Phenotype by Histone Deacetylase Activity. PLoS One (2015) 10(7):e0132984. doi: 10.1371/journal.pone.0132984

180. Thangavel J, Samanta S, Rajasingh S, Barani B, Xuan YT, Dawn B, et al. Epigenetic modifiers reduce inflammation and modulate macrophage phenotype during endotoxemia-induced acute lung injury. J Cell Sci (2015) 128(16):3094-105. doi: 10.1242/jcs.170258

181. Michaels PJ, Kobashigawa J, Laks H, Azarbal A, Espejo ML, Chen L, et al. Differential expression of RANTES chemokine, TGF- $\beta$, and leukocyte phenotype in acute cellular rejection and quilty B lesions. J Heart Lung Transplant (2001) 20(4):407-16. doi: 10.1016/S1053-2498(00)00318-1

182. Bergler T, Jung B, Bourier F, Kühne L, Banas MC, Rümmele P, et al. Infiltration of Macrophages Correlates with Severity of Allograft Rejection and Outcome in Human Kidney Transplantation. PLoS One (2016) 11(6): e0156900. doi: 10.1371/journal.pone.0156900

183. Chu Z, Sun C, Sun L, Feng C, Yang F, Xu Y, et al. Primed macrophages directly and specifically reject allografts. Cell Mol Immunol (2020) 17(3):23746. doi: 10.1038/s41423-019-0226-0

Conflict of Interest: The authors declare that the research was conducted in the absence of any commercial or financial relationships that could be construed as a potential conflict of interest.

Copyright $\odot 2020$ Ordikhani, Pothula, Sanchez-Tarjuelo, Jordan and Ochando. This is an open-access article distributed under the terms of the Creative Commons Attribution License (CC BY). The use, distribution or reproduction in other forums is permitted, provided the original author(s) and the copyright owner(s) are credited and that the original publication in this journal is cited, in accordance with accepted academic practice. No use, distribution or reproduction is permitted which does not comply with these terms. 